\title{
BEAM DUMP AND LOCAL SHIELDING LAYOUT AROUND THE ITEP RADIATION TEST FACILITY
}

\author{
YURY TITARENKO, VIACHESLAV BATYAEV,* ALEXEY TITARENKO, \\ MICHAEL BUTKO, KIRILL PAVLOV, SERGEY FLORYA, \\ ROMAN TIKHONOV, PAVEL BOYKO, and ALEXEY KOVALENKO \\ Institute for Theoretical and Experimental Physics, Moscow 117259, Russia
}

\section{NIKOLAI SOBOLEVSKY}

Institute for Nuclear Research of the Russian Academy of Science Moscow 117312, Russia

VASILY ANASHIN Institute of Space Device Engineering Moscow 111250, Russia

STEPAN MASHNIK Los Alamos National Laboratory Los Alamos, New Mexico 87545

WACLAW GUDOWSKI Royal Institute of Technology Stockholm S-106 91, Sweden

NIKOLAI MOKHOV and IGOR RAKHNO Fermilab Batavia, Illinois 60510-5011

Received April 18, 2008

Accepted for Publication January 6, 2009

The Radiation Test Facility (RTF) is under construction at the Institute for Theoretical and Experimental Physics to control the electronics under irradiation of particles that imitate cosmic rays (protons, carbon, aluminum, iron, tin, bismuth, and uranium). For the norms of radiation safety of personnel and users of the RTF to be observed, a local shielding and beam dump must be designed. Simulations of the dose rates around the designed shielding and beam dump are carried out in the present work.

\section{INTRODUCTION}

Cosmic ray-induced single event upsets (SEU) in microelectronics recently became the dominant problem in terms of providing reliability of spacecraft equipment.

*E-mail: vfb@itep.ru
The characteristics of the cosmic ionizing radiation sources (the Earth's inner and outer radiation belts, the galactic and solar cosmic rays) have been studied in sufficient detail. Low-energy protons produce the radiation dose effects that induce parametric and functional upsets. Ions and high-energy protons induce single radiation effects, resulting in reversible (malfunction) and irreversible (catastrophic) upsets. Analysis of the flighttime onboard equipment upsets has shown that SEU constitute 25 to $35 \%$ of all upsets, so the design of the test facility for direct controlling of SEU is extremely important.

\section{DESCRIPTION OF THE TEST FACILITY}

Direct tests of microelectronics to resist SEU will be realized in the Radiation Test Facility (RTF) using the external proton and heavy-ion beams extracted from the unique heavy-ion accelerator-accumulator complex, i.e., terawatt accumulator (the TWAC-ITEP project). ${ }^{1}$ The RTF beams are planned to have the following basic parameters: 
1. 10-, 15-, 20-, 25-, 35-, 45-, 55-, 65-, 75-, 85-, $100-, 150-, 200-$, and $400-\mathrm{MeV}$ proton energies

2. $1 \times 10^{4}, 3 \times 10^{4}, 1 \times 10^{5}, 3 \times 10^{5}, 1 \times 10^{6}$, and $3 \times$ $10^{6} \mathrm{p} / \mathrm{s} \cdot \mathrm{cm}^{-2}$ (all energies) and $1 \times 10^{7} \mathrm{p} / \mathrm{s} \cdot \mathrm{cm}^{-2}$ (for 10 to $100 \mathrm{MeV}$ ) proton fluxes

3. ion energies (operation mode No. 1): ${ }^{12} \mathrm{C}, 45$ $\mathrm{MeV} / \mathrm{A} ;{ }^{27} \mathrm{Al}, 70 \mathrm{MeV} / \mathrm{A} ;{ }^{56} \mathrm{Fe}, 90 \mathrm{MeV} / \mathrm{A} ;{ }^{120} \mathrm{Sn}$, $120 \mathrm{MeV} / \mathrm{A}$; ${ }^{209} \mathrm{Bi}, 150 \mathrm{MeV} / \mathrm{A}$; and ${ }^{238} \mathrm{U}$, $150 \mathrm{MeV} / \mathrm{A}$

4. ion energies (operation mode No. 2): ${ }^{12} \mathrm{C}, 18$ $\mathrm{MeV} / \mathrm{A} ;{ }^{27} \mathrm{Al}, 32 \mathrm{MeV} / \mathrm{A} ;{ }^{56} \mathrm{Fe}, 23 \mathrm{MeV} / \mathrm{A} ;{ }^{120} \mathrm{Sn}$, $33 \mathrm{MeV} / \mathrm{A} ;{ }^{209} \mathrm{Bi}, 41 \mathrm{MeV} / \mathrm{A}$; and ${ }^{238} \mathrm{U}, 32 \mathrm{MeV} / \mathrm{A}$

5. ion fluxes: $1 \times 10^{2}, 3 \times 10^{2}, 1 \times 10^{3}, 3 \times 10^{3}$, and $1 \times 10^{4}$ ion $/ \mathrm{s} \cdot \mathrm{cm}^{-2}$

6. nonuniformity: $15 \%$ within 15 -mm diameter.

The beams with the above parameters will be formed by directing the accelerated particles from the accelerator ring to the transport channel via the slow extraction system with an $\sim 10^{11}$ particle/pulse intensity for protons and an $\sim 10^{4}$ to $\sim 10^{6}$ particle/flux intensity for ions. The proton energies below $25 \mathrm{MeV}$ are attained using a wedge degrader.

\section{THE INPUT DATA ON PARTICLE BEAM PARAMETERS}

The above energy, flux density, and nonuniformity requirements of proton beams were taken to be the input particle beam data for dose rate simulations. Table I presents the proton and ion beam parameters, which were determined assuming that the beam lateral distribution is normal.

\section{GEOMETRY AND ARRANGEMENT OF RADIATION SHIELDING AND BEAM DUMP}

Figure 1 shows the simulation version of the geometry and arrangement of the shielding blocks (around the aperture and final collimators) and the beam dump. The shielding block consists of two high-density concrete walls of $2.4 \mathrm{t} / \mathrm{m}^{3}$ density, 0.5- to $0.6-\mathrm{m}$ thickness, and $2.4-\mathrm{m}$ height. The walls are placed along the beam line at $1.5 \mathrm{~m}$ from the beam line. The wall length at the corridor side is $9.1 \mathrm{~m}$, and the opposite wall length is $6.5 \mathrm{~m}$.

The beam dump placed at $8.8 \mathrm{~m}$ from the beam extraction point is a heavy concrete cube of 3.6-m depth. A hole of $10-\mathrm{cm}$ diameter and $0.5-\mathrm{m}$ depth is bored in the blind flange at the beam level height. The hole is used to pass the beam to the dump inside.

\section{SIMULATION TECHNIQUES}

The space distributions of dose fields were calculated using the MCNPX code ${ }^{2}$ with the "Mesh Tally" technology that plots the calculated values in rectangular and cylindrical geometries. The SHIELD code ${ }^{3}$ was used to simulate the neutron source space-energy distribution of neutrons produced by heavy-ion beams. The data in Secs. III and IV were used to prescribe the model geometry and the source parameters. Among the elements that surround the RTF, only the shield wall geometry was included in the calculations. The contributions from the instantaneous gamma-quanta and from the activation radiation to the dose rate were disregarded.

The dose rates in the controlled regions (see Fig. 1) were repeatedly calculated at different proton beam energies from 50 to $1600 \mathrm{MeV}$.

TABLE I

The Input Beam Parameters to Simulate Dose Levels

\begin{tabular}{|c|c|c|}
\hline Parameter & Formula & Value \\
\hline $\begin{array}{l}\text { Irradiation time-averaged flux on beam axis, } \Phi_{0} \\
\text { Collimated beam diameter, } D \\
\text { Flux nonuniformity within diameter } d: W=\left(\Phi_{0}-\Phi_{d}\right) / \Phi_{0}, W \\
\text { Nonuniformity determination diameter, } d \\
\text { Pulse repetition rate, } T \\
\text { Pulse duration, } t \\
\text { Mean square deviation, } \sigma \\
\text { The irradiation time-averaged beam current before aperture collimator, } l \\
\text { The irradiation time-averaged beam current after aperture collimator, } I_{c} \\
\text { Flux during a single pulse at the beam axis, } F \\
\text { Proton number per pulse (before the aperture collimator), } N \\
\text { Proton number per pulse (after the aperture collimator), } N_{c}\end{array}$ & $\begin{array}{c}\text { Input value } \\
-/- \\
-/- \\
-/- \\
-/- \\
d \cdot\left[8 \ln (1-W)^{-1}\right]^{-1 / 2} \\
\Phi_{0} \cdot 2 \pi \sigma^{2} \\
I \cdot\left[1-\exp \left(-D^{2} / 8 \sigma^{2}\right)\right] \\
\Phi_{0} \cdot T / t \\
I \cdot T \\
I_{c} \cdot T\end{array}$ & 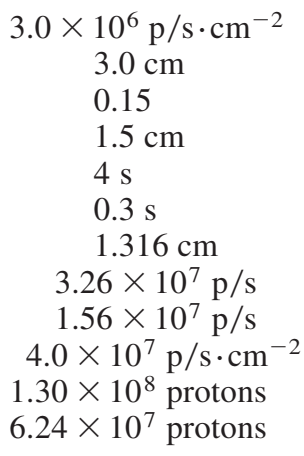 \\
\hline
\end{tabular}




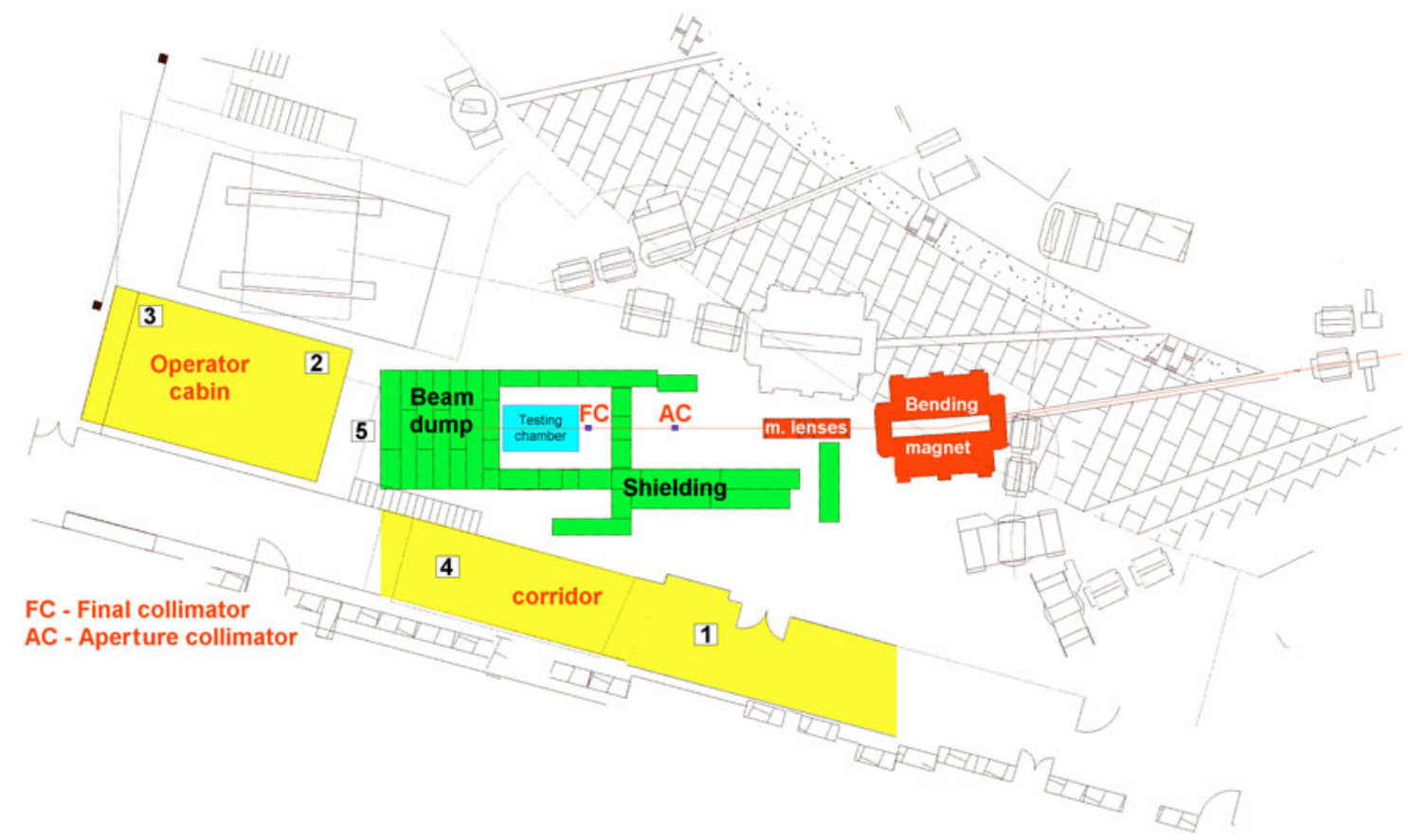

Fig. 1. A schematic of the shielding of the facility and the areas under control. The control points are marked by digits.

\section{THE RESULTS OF SIMULATING THE DOSE RATES}

The calculations have resulted in the space distributions of dose rates. Figure 2 shows some examples of the calculated dose rate distributions around the facility at proton beam energies of 50,100, 200, and $400 \mathrm{MeV}$. Table II presents the numerical values of the dose loads on personnel at $400 \mathrm{MeV}$. Figure 3 shows the maximum dose levels in the corridor zone $D_{K}(E)$ and in the operator cabin $D_{M}(E)$ versus proton beam energy.

\section{TABLE II}

Simulated Dose Loads on Personnel at 400-MeV Proton Energy

\begin{tabular}{|c|c|c|}
\hline $\begin{array}{c}\text { Point in } \\
\text { Fig. 1 }\end{array}$ & Location & $\begin{array}{c}\text { Dose Rate } \\
(\mu \mathrm{Sv} / \mathrm{h})\end{array}$ \\
\hline 1 & $\begin{array}{l}\text { Corridor in front of shielding } \\
\text { blocks } \\
\text { Operator cabin front of the } \\
\text { internal wall } \\
\text { Operator cabin behind the } \\
\text { internal wall } \\
\text { Corridor in front of the } \\
\text { beam dump } \\
\text { The rear butt of the beam } \\
\text { dump }\end{array}$ & $<0.3$ \\
5 & $<$ & 2 \\
\hline
\end{tabular}

Based on a $2000 \mathrm{~h} / \mathrm{yr}$ maximum possible workload of personnel and on Radiation Safety Norm 99 (RSN-99) (Ref. 4), we have obtained the following admissible dose rates for personnel of different categories:

1. category $\mathrm{A}$ (maintenance staff in the corridor zone): $D_{A}=10 \mu \mathrm{Sv} / \mathrm{h}$

2. category B (test staff in the operator cabin): $D_{B}=$ $0.5 \mu \mathrm{Sv} / \mathrm{h}$.

The maximum dose levels versus energy in the corridor and in the operator cabin, shown in Fig. 3, can be readily used together with the admissible dose levels to obtain the highest admissible number of protons in a beam pulse:

$N(E)=N_{\text {Table_1 }} \times \operatorname{minimum}\left[D_{A} / D_{K}(E) ; D_{B} / D_{M}(E)\right]$.

Figure 4 shows the resulting dependence $N(E)$.

\section{CONCLUSIONS}

The proposed versions of the shielding and the beam dump provide the dose loads on the personnel of category $\mathrm{A}$ in the corridor and in the operator cabin at a level admissible in terms of radiation safety $(5 \mu \mathrm{Sv} / \mathrm{h}$ as in RSN-99), which allows for a twofold margin to validate the RTF project everywhere. The dose level for persons 

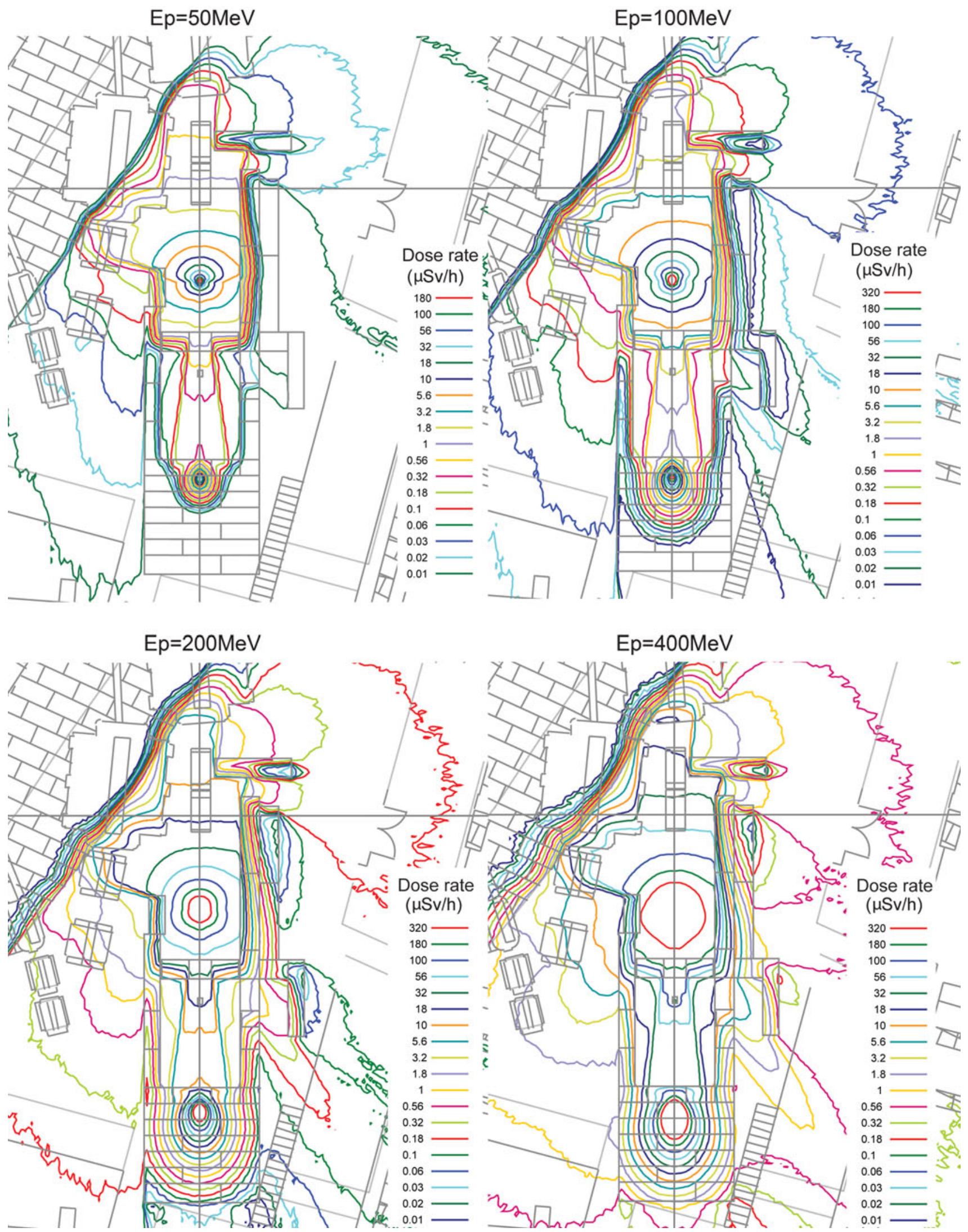

Fig. 2. The simulated dose distributions around the shielding at proton beam energies of 50, 100, 200, and $400 \mathrm{MeV}$. Note that the simulation used a simplified geometry description of the elements located outside the RTF shielding and beam dump. 


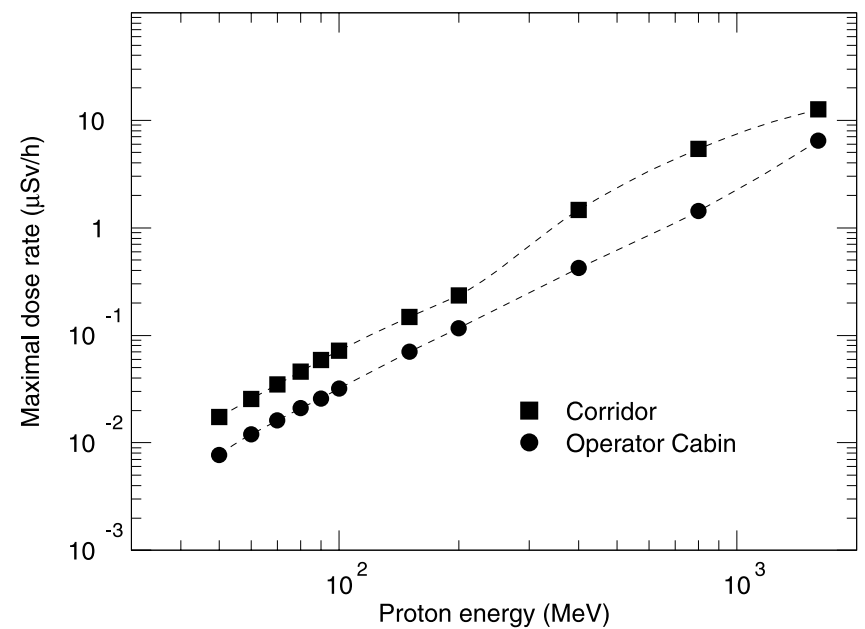

Fig. 3. The maximum dose in the zones under control versus beam energy.

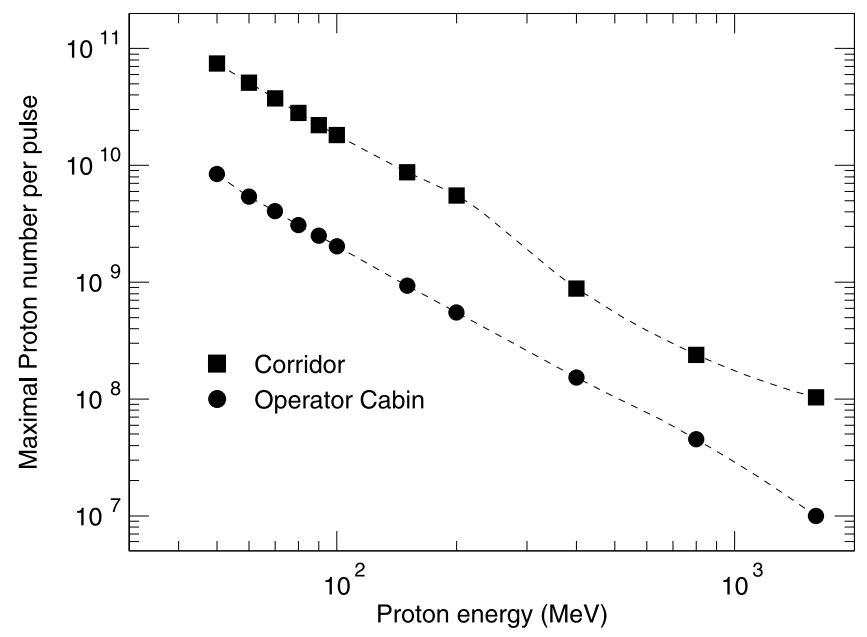

Fig. 4. Admissible numbers of protons in a beam pulse related to radiation load on personnel in the operator cabin and in corridor. of "test staff" category B is provided in the operator cabin (below $1 \mu \mathrm{Sv} / \mathrm{h}$ ).

The energy dependence of the found dose rates shows that the admissible beam pulse rate exceeds $\sim 1 \times 10^{10}$ protons at proton beam energies below $50 \mathrm{MeV}$.

\section{ACKNOWLEDGMENTS}

The work has been supported by the Federal Atomic Energy Agency of Russia; the Federal Space Agency of Russia; and, in part, by the U.S. Department of Energy at Los Alamos National Laboratory under contract DE-AC52-06NA25396.

\section{REFERENCES}

1. B. YU. SHARKOV et al., Nucl. Instrum. Methods A, 464, 1 (2001).

2. J. S. HENDRICKS et al., "MCNPX EXTENSIONS Version 2.5.0," LA-UR-05-2675, Los Alamos National Laboratory (Apr. 2005); available on the Internet at http:// menpx.lanl.gov/.

3. A. V. DEMENTYEV and N. M. SOBOLEVSKY, "SHIELD_Universal Monte Carlo Hadron Transport Code: Scope and Applications," Radiat. Measurements, 30, 553 (1999).

4. "Radiation Safety Norms (RSN-99)," Public Health Ministry of Russia (1999) (in Russian). 